\title{
LA PRESENCIA DE LOS ENLACES EXTRAORACIONALES EN LA TRADICIÓN GRAMATICAL ESPAÑOLA: LA DESCRIPCIÓN DE ALGUNAS CONJUNCIONES. OTROS VALORES CONVERSACIONALES .
}

\author{
Salvador Pons Bordería \\ (Universidadde Valencia)
}

\begin{abstract}
RESUMEN
It is commonly thought that the grammars written before this century contain no remarks about pragmatics. Consacrated to the description of the morphosintactic structure of language, the grammarians would have not been able to «go further» and enter into the realm of language in use. Nevertheless, a revision of the most important grammars of the Spanish tradition shows that this assumption is not entirely true. In the description of some of the most conspicuous connectives a flow of observations can be found, ranging from their textual-organization capacities to their uses in conversation. Against the commonly admited state-of-the-art, we claim for a new and broader revision of the pragmatic observations hidden in the syntactic descriptions of the Spanish grammarians.
\end{abstract}

\section{Introducción}

El presente trabajo tiene por objeto poner de relieve la importancia que, para el estudio de los llamados enlaces extraoracionales, tienen las observaciones que la tradición gramatical hizo sobre estos elementos. En esta ocasión, se revisarán los usos extraoracionales que poseen algunas conjunciones en la tradición gramatical, puesto que la coincidencia de los gramáticos en señalar valores especiales, enfáticos o continuativos de algunas conjunciones hace ver que los usos no oracionales estaban también presentes en la descripción gramatical. Además, se mencionará otro tipo de usos, no tanto extraoracionales como pragmáticos (muletillas, usos enfáticos, ordenadores del discurso y extraoracionales) que también aparecen en la tradición española. Este intento por recuperar las observaciones de nuestra tradición no hace más que seguir el consejo de Antonio Narbona, cuando abogaba por dar apellidos a la sintaxis, 
como medio de completar su descripción. Los apellidos paterno y materno que debe poseer la sintaxis, siempre según Narbona, son los de «coloquial» y de «histórica»' y este trabajo, situado en la esquina de ambos campos, pretende, desde la historiografía lingüística, contribuir a dicha labor heráldica.

\section{Usos especiales de algunas conjunciones}

A pesar de situarse en el marco oracional, muchos gramáticos han visto en determinados usos de las conjunciones valores que sobrepasaban dicho ámbito de acción. Un repaso de la historia de las gramáticas españolas muestra, además, que la atención sobre algunas unidades es recurrente. Intentando reflejar dicha tendencia, esta sección presenta los comentarios de carácter extraoracional que sobre las conjunciones $y$, pues, sin embargo, no obstante, con todo, conque y luego aparecen en distintas gramáticas. La selección de unidades se ha realizado siguiendo el criterio de la productividad; en este sentido, se recogen las unidades más ricas en comentarios de este tipo. Con respecto a los usos, y dentro del carácter unitivo de las conjunciones, se pueden distinguir dos apartados: unión con el co-texto precedente o unión con el contexto ${ }^{2}$.

\section{A. Y}

La multiplicidad de valores de la conjunción copulativa ha sido señalada desde antiguo. BELLO, A. (1988: 1847) ya llamó la atención sobre los usos de $y$ en posición inicial absoluta de discurso:

«Pierde el oficio de conjunción y toma el de simple adverbio en interrogaciones y exclamaciones directas. Fr. Luis de León principia así una de sus odas:

$\ll_{i}$ Y dejas, Pastor santo

Tu grey en este valle hondo, escuro?»

«i Y que no viese yo todo eso!» exclama el héroe de Cervantes al oír una descripción que le hace su escudero. Fácil es percibir la énfasis de esta conjunción adverbializada así. Principiando por una palabra que regularmente supone otras anteriores, se hace entrever confusamente un conjunto de ideas sobre las cuales salta el que habla, para fijarse en la más importante» $(769)^{3}$

Vid. NARBONA (1989).

2 Co-texto: conjunto de elementos de un texto que rodean a un enunciado (LEWANDOWSKI, T. 1982:81). Contexto: conjunto de circunstancias extralinguíísticas que ayudan a la interpretación de un texto (VAN DIJK, T. 1980).

Salvá, en su cap. XVIII, estuvo a punto de distinguir el mismo valor. 
La dificultad para explicar este uso desde la gramática tradicional obliga a Bello a incluir este uso dentro del flexible concepto de adverbialización. El adverbio, por su heterogeneidad formal, es la única categoría que permite acoger usos de este tipo, en los que se producen efectos secundarios, externos a la función primaria de la conjunción, como sucede en este caso con el énfasis. Recordemos que Bello utiliza el término adverbialización en otros lugares de su Gramática ${ }^{4}$, en los que se enfrenta a los usos desplazados de algunas conjunciones, o en los que incluye dentro de la categoría de adverbios a unidades que sólo lo son en virtud de su valor modal, como afirma Bello con respecto del adverbio de afirmación.

La adverbialización es la solución más coherente si se tiene en cuenta que la descripción de Bello considera a la conjunción, y sólo a ella, como responsable de este énfasis. Por dicha razón, el tipo de modificación que se le supone es similar al expresado mediante un adverbio de frases. Si Bello, en vez de mirar hacia la oración tratando de explicar el énfasis, hubiese mirado hacia el contexto, manteniendo el valor de la conjunción, habría coincidido plenamente con la opinión actual, que ve en la conjunción un elemento de unión, no entre dos segmentos verbales, sino entre un segmento verbal y el contexto anterior, no verbal.

La Gramática de la Academia incluye en su edición de 1854, tal vez por influencia de Bello, el valor de y como elemento de unión, no con una oración anterior, sino con el contexto previo, a partir del mismo ejemplo:

«A veces se principia período con la conjunción y, que en ciertos casos no se une a palabras o cláusulas anteriores, sino a reflexiones mentales, que hacen prorrumpir con particular énfasis en exclamaciones como aquella de Fray Luis: ¿Y dejas, Pastor Santo...?» (128)

Este párrafo se mantiene, con ligeras modificaciones de redacción, en ediciones sucesivas de la G.R.A.E., excepción hecha de la edición de 1855. Sólo en el Esbozo la acción directa de Gili Gaya reconocerá de forma explícita el valor de enlace extraoracional que asume la conjunción en este caso ${ }^{6}$ :

BELLO (1988:1847, 613). También en Bello ocurre el fenómeno contrario, es deçir, que un adverbio relativo pase a funcionar como una conjunción. Es los que ocurre con pues (Bello 1988:1847, 341), donde se produce el paso preposición >adverbio relativo > conjunción.

5 Una explicación parecida, expresada en términos pragmáticos, puede verse en BERRENDONNER (1983).

- Hay que señalar, sin embargo, que, al hablar Gili Gaya de enlace extraoracional, está empleando el concepto acuñado por él mismo con un significado ligeramente distinto al que utiliza en su Curso.... En efecto, de la lectura de este último se desprende que los enlaces extraoracionales ya no son sólo elementos utilizados para expresar «transiciones mentales que van más allá de la oración», sino que se convierten en procedimientos utilizados para crear cohesión a nivel textual (y una comparación con los procedimientos listados por HALLIDAY, M.A.K. y R. HASAN(1976) mostrará una sorprendente coincidencia con el capítulo del gramático español). El uso hecho en este caso demuestra una extensión tal vez intuitiva del concepto para cubrir las referencias al contexto extralinguístico. 
«El uso de la conjunción y al comienzo de la cláusula es un enlace extraoracional con lo anteriormente dicho o pensado; p.ej.: $Y$ Y dejas, Pastor Santo, /tu grey en este valle hondo, escuro...?[...] Este empleo de la conjunción es especialmente frecuente en oraciones interrogativas y exclamativas.» (507)

Insistiendo sobre este punto, añade el siguiente comentario, ausente de la edición del 31:

«En otras condiciones denota transición a otro aspecto o parte del asunto que tratamos; p.ej.: Y examinemos ahora la segunda proposición» (ibid)

Se trata en este caso del valor extraoracional de la conjunción que ALCINA FRANCH, J. y BLECUA, J.M. (1975) denominan ordenador del discurso. De este modo, en el Esbozo aparecen de forma explícita los dos tipos de unión extraoracional para la conjunción copulativa: la unión con el co-texto y la unión con el contexto. Contrasta esta aparición con la supresión de las ilativas como subgrupo dentro de las conjunciones y con la inserción de las proposiciones dentro del marco oracional, aunque es consecuente con el carácter ecléctico que mantiene el Esbozo en lo referente al tema de los enlaces extraoracionales.

\section{B. Pues}

Esta ha sido una unidad en la que muchos gramáticos han fijado su atención. La primera referencia en el material utilizado se halla en el Diálogo de la lengua de Juan de Valdés, aunque el autor no se refiere a esta unidad como enlace extraoracional, sino como muletilla (vid. infra). Con el mismo valor aparece también en Covarrubias.

Como conjunción continuativa aparece clasificada en CORREAS, G. (1984:1627, 191):

«Continuativas son pues, mientras, quando, como, con tal, que, con tal que. Digo pues mi cuento, io leo mientras tu escrives, iré quando quisieres, harelo como lo ordenares, $\& c$. Todas las conxunziones pudieran rreduzirse a esta espezie».

El valor extraoracional de pues en este caso se deriva del ejemplo de Correas, en el que el enunciado en el que se inserta la conjunción necesita, para ser gramatical, de un enunciado previo al que referirse, precisamente debido a la anafóra que introduce dicha conjunción. También deriva su carácter extraoracional de la existencia misma del grupo de conjunciones continuativas, al que pueden reducirse todas las demás conjunciones, lo que significa que este grupo posee un estatuto especial, consistente en expresar la unión, sin indicaciones de tipo semántico, y sin especificar el ámbito de acción de dicha unión (que en el caso de pues se establece entre oraciones). 
La GRAE, en sus cuatro primeras ediciones, da dos valores para esta conjunción. El primero de ellos es el de conjunción causal (sufre la pena pues lo quieres); el segundo de ellos es el de conjunción continuativa (digo, pues, que sali de aquel peligro). Es evidente el valor extraoracional de este último, ya que, como en Correas, el uso de esta conjunción presupone un contexto verbal o extraverbal anterior a la frase en la que se inserta el pues.

Salvá distingue también dos valores para pues conjunción, forma a la que considera causal e ilativa. Cabe recordar que el uso que Salvá hace de ilativa se aproxima al que entendemos por consecutiva, aunque el ámbito de acción no se especifique:

«Hemos colocado (pág 290) a la partícula pues entre las causales y entre las ilativas porque denota el motivo de una proposición, v.g. Estará enfermo, pues no me escribe; o se refiere por lo monos a él, como en este ejemplo: Pues que tal es el estado de las cosas, trataremos de aplicar algún remedio al mal. Así es que en sus varios usos, que señalamos a continuación, siempre aludimos a los antecedentes del discurso, y como que apoyamos en ellos nuestra extrañeza, pregunta o reconvención» (703)

Aparte de los distintos usos señalados por el autor (704), en los que se pueden reconocer algunos que se podrían calificar de conversacionales ${ }^{7}$,

«[...] En otras [locuciones] robustece las frases de afirmación y amenaza, como Pues no dude Vd. que ha venido; pues yo te lo aseguro; ¿Pues habia yo de callar? En estas oraciones de interrogante equivale además unas veces a por ventura o acaso: ¿Pues he de bajarme yo a suplicárselo? Otras a ¿qué diremos?, como Su persona era extremada: ¿pues su bondad? y en alguna forma ella sola, asociada a otra partícula, a una pregunta enfática, v.g. ¿Pues cómo? ¿pues no? ¿y pues?

En las comparaciones puede hacer los oficios de asi, de la misma manera, v.g. ¿Habéis visto dos lobos que se disputan la presa? Pues no peleaban con menor encarnizamiento los dos combatientes por conseguir la gloria del triunfo."

el mismo autor señala (ibid) que, en posición inicial de cláusula, posee un «sentido general de ilación».

Obsérvese que la mayor parte de estos usos son de tipo extraoracional y corresponden al lenguaje hablado. No se encuentra en toda la tradición gramatical una descripción más exhaustiva de dicha conjunción.

7 MARTíN ZORRAQUINO $(1992,112)$ ha puesto de relieve los usos de esta conjunción, así como los de bien, ya, que, si, no así, entonces, hasta y ni. 
Bello asigna una doble función al pues conjuntivo. En primer lugar, pues indica consecuencia entre las proposiciones que une (341), constituyendo así una conjunción consecuencial ${ }^{8}$. Dicho rótulo no se refiere a las conjunciones consecutivas, como puede verse en el ejemplo que el propio autor da (763):

«Ignorantes los trovadores de la literatura antigua, nada tenían que ver sus composiciones con los poetas latinos; esta literatura fue pues totalmente original, y la primera en que se reflejaron las ideas y sentimientos modernos».

En segundo lugar, se trata de una conjunción continuativa «de que nos servimos para las transiciones» (764):

«Harto mejor sería volverme a mi casa, y no andarme tras vuesa merced, por caminos sin camino, bebiendo mal y comiendo peor. Pues tomadme el dormir; contad, hermano escudero, siete pies de tierra»(ibid)

Obsérvese que tras dicha etiqueta se esconde un uso conversacional, propio del diálogo, aunque no se aprecie de forma clara en el ejemplo debido a su disposición tipográfica.

Las ediciones de la GRAE situadas entre la publicación de la gramática de Bello y 1917 mantienen los dos usos anteriormente señalados de la partícula pues, a los que añaden ahora el valor ilativo, el cual se introduce por primera vez en la edición de $1854^{\circ}$. En las ediciones que ocupan el periodo entre 1917 y 1931 , en las que se procede a una reducción a usos lógicos de las relaciones existentes entre proposiciones dentro de una frase, pues introduce oraciones coordinadas tanto causales como consecutivas, pero, a pesar de ello, se siguen reconociendo los valores ilativo,

«¿No quiere seguir los consejos de su padre? PUES él lo llorará algún día» (310)

\section{extraoracional}

«Estas conjunciones pueden emplearse también al principio de la cláusula, y denotan entonces que lo que se dice en la oración que encabezan es deducción de lo dicho en la cláusula anterior» (ibid)

* Bello no llega a hablar de conjunción consecutiva. Este hecho es importante, porque consecutiva es un término propio de la sintaxis, que hace referencia a una relación de tipo oracional, entre dos cláusulas interordinadas (ROJO, G. 1978). Consecuencial, en cambio, indica la relación de causa-consecuencia existente entre dos enunciados, la cual no tiene por qué estar reducida al marco oracional; se trata, por tanto, de una etiqueta más bien pragmática.

- El término ilativo en la época se reducía a la introducción de una consecuencia lógica, sin tener en cuenta el ámbito de acción de dicha conjunción. 
y continuativo de la conjunción:

«La conjunción pues es también continuativa, y nos servimos de ella en las transiciones, para continuar y apoyar la oración [...] Con ese valor se emplea también al principio de la cláusula» (ibid)

Lenz también señala el valor coordinante continuativo y consecutivo de la partícula pues y a estos usos añade los de conjunción continuativa y partícula enfática $(86)^{10}$.

Gili Gaya distingue los usos causal y consecutivo (296-98), así como los ilativos y continuativos (326), que caen de lleno dentro del uso como enlace extraoracional.

En el Esbozo se repiten los mismos valores (548 y 552), especificando también los valores extraoracionales que asume dicha partícula cuando funciona como conjunción ilativa o continuativa (ibid).

Finalmente, la gramática de Alcina y Blecua incluye pues entre los ordenadorcs del discurso (886). Además, en el apartado dedicado a las construcciones con pues, distinguen los siguientes usos, en los que la conjunción expresa las siguientes relaciones extraoracionales:

-De consecuencia lógica: «[...] La consecuencia se deduce de lo dicho en la oración precedente; pero, con frecuencia, se presupone un supuesto no expreso, implicado por lo dicho» (1183)

Le repugnaba algún manjar de la mesa; pues se imponía la penitencia de comerlo dejando en cambio, otros que le placían extremadamente (ibid)

-Continuativo o inicial: «Esta última posibilidad [la que acabamos de citar] le permite comenzar el discurso enlazando con lo dicho o simplemente con lo pensado o sugerido por la conversación o como simple recurso de iniciación:

'Pues anda que los antecedentes de éste[...]'» (ibid)

Como puede observarse, un buen número de autores, a lo largo de toda la historia de la gramática española, ha coincidido en señalar los usos extraoracionales de pues. Su unanimidad es una prueba de que los gramáticos han sido capaces de incorporar a la descripción de la lengua los usos más cotidianos y extendidos de dicha conjunción, aunque pertenezcan al lenguaje hablado.

\section{Sin embargo, no obstante, con todo}

La primera referencia que hemos encontrado sobre tales unidades se encuentra en El Brocense, aunque es de suponer que estas unidades se mencionen en gramáticas anteriores en las que se distinga el subgrupo de las conjunciones

Sobre el concepto de partícula enfática, vid. infra. 
adversativas (cosa que ocurre en Percyvall, Charpentier, Oudin, Sanford, Fray Diego de la Encarnación y Franciosini, apud RAMAJO CAÑO, A. (1987, 203204). La mención al término sin embargo, siguiendo a GÓMEZ ASENCIO, J.J. $(1985,179)$, parece ser frecuente para el período comprendido entre $1771 \mathrm{y}$ $1847^{11}$; no obstante y con todo no aparecen en este subgrupo.

Bello se refiere a la partícula no obstante como preposición originada de una cláusula absoluta que, cuando funciona sin término, hace el oficio de una conjunción adversativa (740), a pesar de lo cual no señala ningún uso extraoracional.

Será GILI GAYA, S. $\left(1983^{12}\right)$ el que señale el carácter extraoracional de estas locuciones al señalar que

«Las frases conjuntivas sin embargo, no obstante y con todo, indican a menudo transiciones en el sentido general del discurso; es decir, su valor de nexo va más allá de las oraciones que gramaticalmente coordinan. Cuando un escritor comienza cláusula diciendo: Intentaré, sin embargo, contestar a las principales objeciones..., hace una referencia a todo lo dicho antes». (284)

Este valor se reflejará en el Esbozo..., donde se hará una referencia explícita al valor de dichas unidades como enlaces extraoracionales:

«Muchas de estas locuciones [las adversativas] tienen además el valor de enlaces extraoracionales como remisión a todo lo que precede, especialmente sin embargo, no obstante y con todo» (513)

ALCINA FRANCH, J. y J.M. BLECUA $(1975,886)$ los clasifican dentro de los ordenadores del discurso. Dichos elementos aparecen con frecuencia junto a la conjunción copulativa $y$; para Alcina-Blecua se produce en estos casos una especialización de funciones por la que recae en la conjunción copulativa el valor de unión de los dos segmentos y en las locuciones el valor semántico de puntualizar «de alguna manera lo dicho en el primer miembro» (1186).

\section{Conque}

La aparición de esta conjunción en las descripciones que hemos utilizado es relativamente tardía: se señala su uso en Díaz, Pelegrín y Lacueva, quienes la clasifican como conclusiva, y en Noboa, que la considera terminativa (apud GÓMEZ ASENCIO, J.J. 1985, 179). Dado que sus compañeras en ambas clases de conjunciones son, por un lado, luego y por tanto, y por otro por fin, por último y al cabo, no es de extrañar que su valor extraoracional aparezca de manera más o menos implícita.

\footnotetext{
1 A pesar de no aparecer en la primera edición de la GRAE.
} 
Bello, por su parte, la considera conjunción consecuencial (755-56):

«Con que de tus receta exquisitas (Un enfermo exclamó) ninguna alcanza?» (ibid) ${ }^{12}$

La GRAE comienza a mencionar esta conjunción a partir de 1854 , cuando introduce el subgrupo de las conjunciones ilativas, en el que se incluye la forma conque, junto a «luego, pues, por consiguiente y otras semejantes» (133). En este grupo permanecerá hasta 1917. En dicho año la forma conque se transformará, junto a sus compañeras, en una conjunción introductora de oraciones coordinadas consecutivas. También se la trata como introductora de oraciones subordinadas adverbiales consecutivas, donde se reconoce que, cuando falta la primera oración de la correlación consecutiva, la relación se establece con lo dicho antes o con el contexto:

«Este mismo valor [consecutivo] tiene en las oraciones interrogativas y exclamativas en que se refiere a lo que se ha expresado inmediatamente antes, o a algo sabido de antemano o sugerido por el contexto; v.gr.: ¿CONQUE ESTÁ usted de enhorabuena?» REAL ACADEMIA, E. (1931), 390.

LENZ, R. (1920) la considera conjunción ilativa de consecuencia. Esta clasificación parece una fórmula de compromiso por la cual se reconoce el valor continuativo de dicha partícula (reconocido, por otra parte, en la pág. $86 \mathrm{de} \mathrm{su}$ Gramática) a la vez que se manifiesta el acuerdo con la clasificación de la GRAE, en su edición de 1917. Además de esto, en la pág. 86 se la considera como partícula enfática. Este uso, que se acerca al de las partículas modales alemanas, es más bien de tipo pragmático.

Clasificada en el apartado de las conjunciones coordinadas consecutivas aparece en ALONSO, A. y P.H. UREÑA (1938, 178). Como subordinada sustantiva consecutiva la trata GILI GAYA, S. $\left(1983^{15}, 298\right)$; en el Esbozo... aparece dentro del grupo de las subordinadas circunstanciales consecutivas (552). Si bien los usos reflejados en dichas clasificaciones son de tipo oracional, en ambas obras de Gili Gaya se reconoce también el valor ilativo y continuativo de dicha conjunción ${ }^{13}$.

\section{E. Luego}

Esta conjunción aparece, según el material manejado por nosotros, en Díaz, Peregrín y Lacueva (apud GÓMEZ ASENCIO, J.J. 1985, 179) como conjun-

12 Es de destacar que, tanto en los autores mencionados anteriormente como en Bello, dicha conjunción se escribe separada: con + que.

${ }^{13}$ GILI GAYA, S. $\left(1983^{15}, 326\right)$ y REAL ACADEMIA $(1973,552) .{ }^{14}$ Reproducido también en BRIZ GÓMEZ, A.(1994). 
ción conclusiva, junto a por tanto y a conque. Gómez Asencio considera que este grupo es equivalente al de las ilativas, y así parece ser, dada la nómina de unidades que componen a este grupo (por tanto, conque, pues). Una clasificación muy parecida puede encontrarse en Bello, para quien esta conjunción puede funcionar como deductiva y, dentro de este subgrupo, como consecuencial.

En gramáticas posteriores (REAL ACADEMIA, E. (1917); REAL ACADEMIA, E. (1931); ALONSO, A. y P.H. UREÑA (1938); SECO, R. (196310); REAL ACADEMIA, E. (1973); GILI GAYA, S. (1983 $\left.{ }^{15}\right)$ su clasificación es paralela a la de conque. La única diferencia radica en que luego se toma siempre como conjunción copulativa, por lo que no aparece en los grupos de las subordinadas, como ocurría con conque.

ALCINA FRANCH, J. y J.M. BLECUA $(1975,886)$ la consideran un ordenador del discurso. Sus usos se analizan en la sección de «yuxtaposición y ordenadores léxicos» (1138-1155). Luego se considera un ordenador

«que tanto puede marcar la ordenación del discurso como desempeñar otras funciones determinadas en la comunicación»(1141).

Como tal se analiza en las págs. 1146-1147, donde se señala su valor coordinante en posición inicial absoluta, donde la causa «queda sobreentendida o por lo que se ha dicho anteriormente en el diálogo o por lo que ha pensado y no expresa el hablante». Este mismo caso se sitúa en el Esbozo... dentro de los usos como enlace extraoracional de las conjunciones que introducen oraciones subordinadas consecutivas (552).

\section{Otros valores conversacionales}

Los usos extraoracionales de las conjunciones no son los únicos usos de tipo no oracional que se encuentran en nuestra tradición gramatical. En esta sección se recogen más referencias a dichos usos: las muletillas o bordones, los casos de énfasis y los ordenadores del discurso. Todos ellos guardan una estrecha relación, desde un punto de vista pragmático, con las dificultades que plantea la planificación del discurso oral. Si bien los testimonios aquí aportados son bastante escasos, es posible que existan más en otras gramáticas, diálogos o tratados de enseñanza del español para extranjeros.

\section{A. Bordoncillos y muletillas}

Los términos bordón, muletilla y expletivo poseen un alcance muy parecido, siendo el uso de uno u otro elemento dependiente de la época histórica o de la definición con que los bautice el autor en cuestión. De su antigüedad, y de su pervivencia hasta el presente, nos ocuparemos brevemente a partir de los comentarios que realizan sobre ellos diversos autores: 


\section{-Juan de Valdés}

En este autor se encuentra ya una referencia a dicho término, aunque quizás se trate de una denominación ampliamente aceptada en su época y aparezca en testimonios anteriores. En su Diálogo de la lengua se puede hallar el siguiente comentario ${ }^{14}$ :

«MARCIO.- [...] Y si queréis que alabemos vuestra prudencia con esto y que os tengamos en merced la honra que nos hazéis en ello, no nos desavernemos con tal que nos digáis qué quieren dezir ciertas palabrillas que algunas personas en su habla usan ordinariamente, las quales ni se scriven ni tampoco me acuerdo oíroslas dezir jamás a vos.

VALDÉS.- ¿qué suerte de palabras es essa? Dezidme alguna dellas.

MARCIO.- Aqueste, pues, assí, no sé qué, etc.

[...]

VALDÉS.- Y tornando a nuestra materia, digo que el no sé qué es muy diferente dessotras partezillas, porque el no sé qué tiene gracia, y muchas vezes se dize a tiempo que sinifica mucho. Pero essotras partezillas son bordones de necios.

MARCIO.- ¿Qué llamáis bordones?

VALDÉS.- A essas palabrillas y otras tales que algunos toman a que arrimarse quando, estando hablando, no les viene a la memoria el vocablo tan presto como sería menester. Y assí unos ay que se arriman a ¿entendéisme? y os lo dizen muchas veces, sin aver cosa que importe entenderla o que sea menester mucha atención para alcançarla, por donde concéis que no os preguntan si los entendéis por dubda que tengan dello, sino porque, mientras os preguntan aquello, les venga a la memoria lo otro. Otros ay que por la mesma razón se arriman a no sé si m'entendéts, aunque conozcan claramente que son entendidos. Otros dizen: ¿estáis conmigo?, que vale tanto como ¿entendéisme?. Otros se sirven de pues, y otros de tal, y repítenlos tantas vezes que os vienen en fastidio grandíssimo. Muchos se sirven de aqueste, y se sirven más dél que de caballo de muchas sillas. Otros se aprovechan de assí, y tras cada palabra os dan con él en los ojos. Otros se sirven de tomé y de tomamos, diziendo: tomé y víneme y tomamos y vinímonos, y si les preguntáis qué es lo que tomaron, no os podrán dezir con verdad sino que aquel vocablo no sirve sino para un malo y feo arrimo. Otros semejantes a estos creo ay, de que yo no me acuerdo. Si más queréis, por buen dinero». VALDÉS, J.d. (1535:1983, 135-136).

De este comentario se puede extraer una serie de conclusiones interesantes: en primer lugar, se trata de una clase de palabras que se emplean en la lengua hablada, no en la escrita. El significado que toman en las ocasiones en que se usan como bordones no corresponde a su significado proposicional, estando

14 Reproducido también en BRIZ GÓMEZ, A.(1994) ${ }^{15}$ BEINHAUER, W. (1929:1978*3); BEINHAUER, W. (1965) se refiere a los usos de determinadas partículas como muletillas, así como YNDURÁIN, F. (1965), quien emplea de forma explícita el término_bordoncillo; en épocas más recientes, aparece también en BARRENECHEA, A.M. (1979); GILI GAYA, S. (1983'5); FUENTES RODRÍGUEZ, C. (1987); FUENTES RODRÍGUEZ, C. (1990); CORTÉS RODRÍGUEZ, L. (1991). La tesis común a todos estos autores es la de que, por determinadas razones (normalmente, debido al desgaste producido por el uso), formas como o sea, pues, bueno etc., pierden su valor originario y se convierten en formas huecas, convirtiéndose así en "palabras o locuciones en que apoyan su elocución las personas no instruidas o poco dueñas de los recursos idiomáticos [...] Tales muletillas están desposeídas de su significado y función normales, y pasan a ser vagas indicaciones de continuidad o enlace, y a veces simples rellenos».GILI GAYA, S. (1983 $\left.{ }^{15:} 326\right)$. 
ligados sus valores a la estructura de la conversación; son, usando términos más actuales, elementos relacionados con problemas de planificación del discurso hablado, el cual es mucho más rápido en cuanto a su producción que el escrito (CHAFE, W.L. 1982), y está sujeto a cambios en la orientación de lo expresado (SORNICOLA, R. 1981). Despojando al texto de su tono normativo, nos encontramos con otro dato interesante, como es la aparición del elemento pues como muletilla. Este hecho parece apoyar la hipótesis de MARTÍNEZ GARCÍA, H. (1991) para quien la fijación de usos de dicha partícula sucedió relativamente temprano en la historia de la lengua.

\section{-Covarrubias}

Covarrubias repite la idea de Valdés en su Tesoro..., en el que da la siguiente definición del término bordón:

«Quando alguno tiene por costumbre, yendo hablando, entremeter alguna palabra que la repite muchas vezes y sin necesidad, dezimos que es aquel su bordonzillo, porque entretanto descansa en él y piensa lo que ha de dezir, como: Bien me entiende V.M.; Sepa V.M.; Ya digo; Por manera, Señor, y otras palabras semejantes a éstas» (229)

Dada la concepción tradicional de la gramática, este término parece haber sido asociado más al reino de la lexicografía que al de la sintaxis propiamente; si no, es difícil explicar cómo un término, bien conocido por lo que se puede ver en los testimonios precedentes, no aparece en otras gramáticas de la época. En una época más reciente, la definición de muletilla aplicada a las conjunciones y a otros elementos de tipo conectivo se ha hecho término frecuente en los estudios sobre español coloquial ${ }^{15}$ pero su reflejo en una gramática es más bien escaso, excepción hecha de obras como el Curso... de Gili Gaya.

\section{B. Énfasis}

Bajo este rótulo se encuentran determinados usos atribuidos por parte de la tradición gramatical a la intensidad con que se pronuncia algo, los cuales suelen

\footnotetext{
${ }^{15}$ BEINHAUER, W. (1929:19783); BEINHAUER, W. (1965) se refiere a los usos de determinadas partículas como muletillas, así como YNDURÁIN, F. (1965), quien emplea de forma explícita el término bordoncillo; en épocas más recientes, aparece también en BARRENECHEA, A.M. (1979); GILI GAYA, S. (1983 $\left.3^{15}\right)$; FUENTES RODRÍGUEZ, C. (1987); FUENTES RODR IGUEZ, C. (1990); CORTÉS RODRÍGUEZ, L. (1991). La tesis común a todos estos autores es la de que,

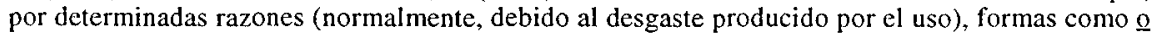

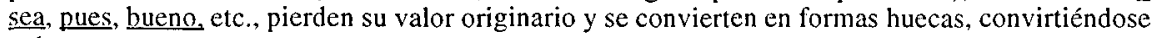
así en

«palabras o locuciones en que apoyan su elocución las personas no instruidas o poco dueñas de los recursos idiomáticos [...] Tales muletillas están desposeídas de su significado y función normales, y pasan a ser vagas indicaciones de continuidad o enlace, y a veces simples rellenos».GILI GAYA, S. (1983 15: 326).
} 
lindar con el valor extraoracional. Ya hemos mencionado el caso de la partícula $y$ inicial, cuyo valor, tanto en la GRAE como en Bello, atribuía al énfasis la necesidad de establecer una unión con los pensamientos (o con el estado de cosas) precedentes. Existen otras muestras en la tradición gramatical de dichos usos enfáticos en las conjunciones.

-Lenz

Lenz concibió una clase de palabras agrupada en torno al énfasis. Se trata de las llamadas partículas enfáticas:

«Existe otra clase más de palabras que merece ocupar un lugar especial en la clasificación de las partes de la oración, que sirven para aumentar o rebajar el acento, la importancia que atribuímos a un elemento de la oración o a la idea expresada en conjunto. Estas palabras a menudo tienen el aspecto de fórmulas muy antiguas y primitivas, parientes cercanos de las interjecciones; otras veces se acercan a las conjunciones, sobre todo a las que en castellano se llaman conjunciones continuativas (pues, conque, este último en Chile casi desconocido), o son adverbios y frases adverbiales que han perdido su significado primitivo, como tan sólo (en Chile no más), sin embargo, no obstante, en verdad, propiamente, aun, además, etc., o restos de frases con verbos, como es que, y equivalentes de oración, si que, verdad que, etc. También fórmulas verbales, como vamos, vaya, oye (en Chile de preferencia mire, mira), desempeñan el mismo oficio.» (Lenz 1935: 85-86)

Esta clase funcional, heterogénea desde un punto de vista formal, puede compararse con la de las partículas modales del alemán, como así parecen demostrar los ejemplos de traducción de dichas partículas en español propuestas por el propio autor a continuación de la cita aquí reproducida. En efecto, Lenz parece agrupar la supuesta clase de partículas modales españolas en torno a un eje vertebrador, que sería el énfasis. Todas ellas se caracterizan por poseer un significado proposicional diluido (o de claro matiz modal) y por vehicular una valoración subjetiva cuyo ámbito de acción es toda la oración; en este sentido coincide el gramático chileno con opiniones como las de WEYDT, H. (1969); HELBIG, G. (1977); BUBLITZ, W. (1978); HARTMANN, D. (1979) o KRIVONOSOV, A. (1989) ${ }^{16}$. La diferencia entre una conjunción, un adverbio y una partícula modal queda aclarada a partir de la siguiente cita:

«[las conjunciones coordinantes secundarias] son primitivamente adverbios y frases adverbiales que pierden, ya más, ya menos, su sentido propio de expresar una modificación de la acción misma, y pasan a ser una apreciación por la cual se refuerza o se disminuye el valor de todo lo dicho» (543-544)

16 Por desgracia, la opinión de Lenz no se recoge en trabajos de indole contrastiva, como los de ZIERER, E. (1982) y ACOSTA, L. (1984), en los que se aborda el problema del uso de las partículas modales alemanas y su posible traducción o existencia en español. 
«Compárese el valor del adverbio en estas dos oraciones: Usted puede pasar seguramente por este puente [...] y Seguramente usted puede pasar por este puente [...] Cuando seguramente modifica la acción del verbo, como en el primer ejemplo, es un simple complemento ordinario; en el segundo ejemplo es una 'palabra enfática', que se distingue poco del oficio de una conjunción coordinante, porque indica una relación vaga con lo que se ha dicho con anterioridad, como es más claro en el ejemplo con todavía. Se comprenderá que es muy difícil determinar con exactitud el carácter de tales palabras; pero también que conviene en gramática distinguir las dos funciones. Ya que en castellano hay muy pocas partículas enfáticas relativamente primitivas como pues, y ellas no se usan sólo para tal destino, bastará seguir denominando los giros correspondientes 'conjunciones' o adverbios conjuntivos» (Lenz1935: 544)

También en este punto coincide el autor con los estudios alemanes, en los que se diferencian los usos de un elemento como preposición, adverbio o conjunción, y como partícula modal. Así, no existe inconveniente alguno en que un elemento que en una frase se emplea como adverbio en otra funcione como una partícula modal. A juzgar por la primera cita, la función que desempeñan tales partículas se reduce a marcar el valor enfático de algunos elementos, como hacen pues y pero al principio del enunciado (también citados por la REAL ACADEMIA: 1931:307 y Esbozo 1973:537). Sin embargo, Lenz cita unidades cuyos supuestos usos enfáticos no han sido mencionados por otros gramáticos, como ocurre con no obstante, aún, etc. De la cita anterior, entresacamos una frase que vuelve a precisar esta idea:

«en el segundo ejemplo [vid. cita anterior], seguramente, es una 'palabra enfática' que se distingue poco del oficio de una conjunción coordinante, porque indica una relación vaga con lo que se ha dicho con anterioridad» (Lenz, ibid)

En este punto, el autor parece asimilar el concepto de partícula enfática al de conjunción ilativa, si bien de una manera un tanto imprecisa.

\section{-RAE}

En distintas ediciones de su Gramática se señalan los usos enfáticos de a las conjunciones y pero y pues (este último, sólo desde el Esbozo):

«A veces se principia período con la conjunción y, que en ciertos casos no se une a palabras o cláusulas anteriores, sino a reflexiones mentales, que hacen prorrumpir con particular énfasis en exclamaciones como aquella de Fray Luis: ¿ $Y$ dejas, Pastor Santo...?» (REAL ACADEMIA 1854, 128)

«Pero se emplea también al principio de cláusula sin referirse a otra oración anterior, y sólo para dar énfasis o fuerza de expresión a lo que se dice; v.gr.: PERO ¿quién te ha dicho eso?, PERO iqué hermosa noche!» REAL ACADEMIA, E. (1917, 310)

«Las conjunciones pues, por (lo) tanto, por consiguiente, se emplean además en las transiciones como continuativas [...] La conjunción pues se emplea especialmente con este valor enfático: Pues, como iba diciendo; ¡Pues no faltaba más!»REAL ACADEMIA, E. $(1973,552)$ 


\section{Los enlaces extraoracionales}

El concepto de enlace extraoracional no se corresponde, en su uso actual, al definido por Gili Gaya en su Curso.... Hoy en día se tiende a establecer una relación sinecdótica entre las conjunciones de Gili y los enlaces extraoracionales, olvidando que también la elipsis o el ritmo pueden considerarse como tales. Obsérvese que todo trabajo que se dedique a estudiar los denominados conectores utiliza a modo de quasi sinónimo el término de enlace extraoracional; extraño sería, sin embargo, que dicha equiparación se llevara a cabo en un estudio fonético o estilístico del ritmo en español, o en un artículo que tratara sobre la anáfora. La involuntaria responsable de tal desplazamiento tal vez sea Catalina Fuentes Rodríguez, al haber dado el título de Enlaces extraoracionales a un libro en el que se estudian sólo las conjunciones de Gili Gaya ${ }^{17}$. De ahí la (falsa) equivalencia entre uno y otro términos.

Sin embargo, el concepto de enlace extraoracional, tal y como aparece definido por Gili Gaya, posee un alcance mayor, que se puede equiparar al de procedimientos de cohesión de un texto. Obsérvese si no la siguiente cita del conocido cap. XXIV del Curso...:

«Las oraciones se suceden guardando entre sí una relación de coherencia representativa, lógica o afectiva, una trabazón psíquica de orden superior. Si esta relación de continuidad no se revela, decimos que el discurso es incoherente. La unidad total del discurso, a la cual sirven las oraciones que lo componen, obedece a leyes psicológicas [...] su estudio excede de los límites de la Sintaxis, la cual sólo puede operar en presencia de medios formales de relación lingüística. Como quiera que estos medios formales de enlace quedan en su mayor parte confinados dentro de la oración, nuestro estudio habrá de ceñirse a los recursos de que el idioma pueda valerse para dar expresión gramatical a relaciones que van más allá de la oración» GILI GAYA, S. (1983 $\left.{ }^{15}, 325\right)$ (el subrayado es nuestro)

Si se comparan los apartados del citado capítulo con los procedimientos de cohesión estudiados por HALLIDAY-HASAN(1976), se observará una coincidencia bastante grande entre éstos y los comprendidos bajo el concepto de Gili Gaya:

HALLIDAY-HASAN: Reference, substitution, ellipsis, conjunction, lexical cohesion

GILI GAYA: Repetición, anáfora, elipsis, conjunciones, ritmo

Elipsis y conjunciones son dos elementos comunes a ambas obras; la repetición estaría incluida en parte dentro de la lexical cohesion; y la anáfora sería

17 De dicho desplazamiento es tanto más inocente la autora sevillana cuanto que ella, en su propia obra, no se refiere a las conjunciones como enlaces extraoracionales, sino como enlaces conjuntivos. A phatic function in the discourse, underlying the interactive structure of the conversation. «I distinguish them from the "pragmatic connectives', which also include metatextual connectives, used to mark the structuring of the discourse" (la cursiva es nuestra) 
uno de los elementos de la reference. Sólo quedarían sin relacionar el ritmo y la substitution.

Puede considerarse, por tanto, que, mediante dicho concepto, Gili Gaya introduce un elemento de la lingüística textual avant la lettre, y es en cierto modo sorprendente que dicho precedente no haya sido más puesto de relieve en trabajos inscritos en dicha orientación.

\section{Los ordenadores del discurso (Alcina-Blecua)}

Alcina-Blecua( 1975,886$)$ introducen esta clase funcional, incluida dentro de los denominados elementos periféricos, a la que definen como

«Una variada y bastante extensa serie de unidades [que] se emplea para relacionar la oración con la que le precede o sirve para situarla dentro del discurso en una jerarquía o relación lógica. [...] Se emplean elementos como por tanto, por ello, por eso, con todo, en consecuencia, por consiguiente, pues, luego, asi que, y eso que, sin embargo, no obstante, y otros».

Los ordenadores del discurso poseen una función doble: en cuanto que relacionan oraciones, su función es parecida a la de las conjunciones de Gili Gaya. En la medida en que sirven para jerarquizar, son comparables a los demarcadores de HOCKETT, C. $(1958: 1971,155-156)^{18}$, a la denominada por SCHEGLOFF, E. y SACKS, H. (1973, 307-308) $)^{19}$ monotipical conversation, a los gambits de KELLER, E. (1981) ${ }^{20}$, a los metatextual connectives de BAZZANELLA, C. $(1990,630)^{21}$, a los Gliederungssignale de QUASTHOFF, U. $(1979)^{22}$ y a otras concepciones de los conectores que incluyen la organiza-

18 «Algunos morfemas no funcionan directamente como portadores de significado, sino más bien como demarcadores o señaladores de las relaciones estructurales entre otras formas. $Y$ señala el hecho de que algo que le precede [...] y algo que le sigue [...] son los CCII de una forma gramatical más extensa»

19 "There is a type of overall conversational organization in which bounding a topic [...] is specially relevant, and in which a sequence made up of a topic closing exchange followed by a possible pre-closing is specially prominent, which we shall calll 'monotopical conversation'. With the term 'monotopical' we intend [...] conversations produced from their beginnings with an orientation to their expectable monotopicality [...]. Thus, conversations whose initiator begins with the announcement 'Two things' [...] may serve to counter an otherwise expectable construction of the conversation around one topic».(307-308).

20 Señales verbales usadas para introducir cambios de nivel dentro de la conversación.

2! «By PC's [phatic connectives] I mean those items otherwise variously referred to as 'discourse particles', 'utterance particles', 'marqueurs de fonction interactive', 'particelle conversazionali', 'gesprächpartikeln', "conversazionali', 'gesprächpartikeln', "conversational greasers", etc. which mainly perform conversational greasers", etc. which mainly perform a phatic function in the discourse, underlying the interactive structure of the conversation. I distinguish them from the 'pragmatic connectives', which also include metatextual connectives, used to mark the structuring of the discourse» (la cursiva es nuestra).

22 Gliederungssignale: «Strukturierungssignale auf der Realisationsebene» (43). «Glederungssignale gehören demgegenüber eindeutig zu den interaktiv-motivierten 
ción del discurso como una de sus funciones (SCHIFFRIN, D. (1987b), BERRETTA, M. (1984), entre otros). Las unidades del paradigma hacen pensar, para la segunda de las funciones, en las conjunciones ilativas (portanto, por ello, por eso, con todo, en consecuencia, por consiguiente); la primera de ellas está pensada para los conectores inespecíficos de origen conjuntivo (pues, luego, sin embargo, no obstante). No aparecen, pero sería lícito incluir, a los ordenadores como en primer lugar, en segundo lugar... ${ }^{23}$.

En la tradición gramatical pueden verse, por tanto, referencias no sólo a lo extraoracional, sino también a fenómenos de tipo textual (en especial, referidos al concepto de coherencia), y a características propias del habla, como el énfasis. Como era de esperar, se trata de comentarios más bien escasos, que tocan el tema de pasada (no otra cosa sería esperable en una gramática tradicional) y son más frecuentes cuanto más reciente es la gramática. Pero son tanto más valiosas cuanto más extendida se hace la opinión de que los estudios pragmáticos no pueden hallar en estas obras precedente alguno sobre el que sustentarse.

\section{Conclusión}

Quisiéramos exponer en este apartado una serie de consideraciones finales, a modo de balance global sobre la presencia de los enlaces extraoracionales en la descripción de las gramáticas tradicionales, porque, frente a lo que parece afirmarse tácitamente en los estudios sobre el español hablado, el examen del material manejado por nosotros demuestra que la tradición gramatical española sí que se ha ocupado de ellos. Sus observaciones se pueden agrupar de la siguiente forma:

1. -Usos particulares de determinadas conjunciones y adverbios. En estos usos se reconocen valores extraoracionales (y, pero iniciales) o conversacionales (pues) propios de cada unidad, denominados usos continuativos, enfáticos o iniciales. En cualquier caso, se considera que tales usos no alteran el valor principal de la unidad, y el que una conjunción pueda unir enunciados separados por punto o enlazar un mensaje lingüístico con un estado de cosas anterior, o con ideas precedentes de carácter no verbal, no afecta a su oficio principal. Estos usos no se consideran extraños o disruptivos, sino una especie de extensión de su valor principal, de carácter oracional.

2.- Grupos de conjunciones. Algunos de los tipos de conjunciones reconocidos en las clasificaciones tradicionales agrupan preferentemente unidades de

Strukturierungssingalen, die auf der Ebene der sprachlichen Realisierung des narrativen oder argumentativen Plans [...] angesiedelt sind» (50).

23. Bello indica que «Las frases lo primero, lo segundo, etc., se adverbializan también equivaliendo a en primer lugar, en segundo lugars (613), en un uso similar al de Alcina-Blecua. 
carácter extraoracional. Es lo que sucede con las llamadas conjunciones ilativas y continuativas, que se componen, en la mayoría de las gramáticas hispánicas anteriores al siglo XX, de conjunciones como asípues, por consiguiente, puesto $q u e$, etc. Es cierto que, en Nebrija y Correas, aparecen junto a éstas unidades como pues, cuando, o porque, que se integran en el marco oracional, pero esta mezcla de ámbitos no constituye un problema, ya que ambos gramáticos se limitan a señalar la relación existente entre dos segmentos lingüísticos, sin importarles si esta relación se produce entre palabras, sintagmas, proposiciones u oraciones. El ámbito de acción queda (in)definido por la definición de la conjunción y se sobreentiende en el resto de la descripción. Por eso no nos deben extrañar los comentarios que Nebrija y Correas hacían de las conjunciones continuativas, en los que se juntaban tanto cuando como pues: si ambos elementos señalan una relación de continuidad, la pregunta del rango que poseen los elementos que unen es secundaria. Idéntica observación cabe hacer de la equiparación que se establece en algunos gramáticos entre conjunciones ilativas y consecutivas. El que el segundo enunciado sea una consecuencia del primero no siempre quiere decir que se trate de una proposición dependiente, sintácticamente subordinada a la principal, sino que la relación de significado que establece el conjunto es de causa-consecuencia. Pero en esta concepción nada se dice del estatuto gramatical que deban tener tanto la causa como la consecuencia. La GRAE (1917) yerra al someter la relación semántica de causaconsecuencia al molde sintáctico del concepto de oración; ambos conceptos pueden, pero no siempre deben, coincidir.

Bello merece mención especial en este punto, puesto que, aunque en los distintos tipos de conjunciones distinguidas (deductivas, raciocinativas, consecuenciales, etc.) se vean meras variantes de las conjunciones ilativas y continuativas y, aunque los criterios que le sirven para establecerlos sean de tipo semántico, su aparición revela la necesidad sentida por el gramático venezolano de diferenciar tipos de relación extraoracional.

3.- Otra prueba, en cierta medida inconsciente, de la poca importancia que tiene el ámbito de acción de las conjunciones en muchos de nuestros gramáticos puede hallarse en los ejemplos que ilustran el uso de las conjunciones. Aun tomando un concepto amplio de oración como unión de sujeto más predicado con sentido completo, podrá observarse cómo muchos de los ejemplos que aparecen en Bello, las sucesivas ediciones de la GRAE, etc., presentan conjunciones uniendo oraciones o una oración con un estado de cosas previo, incluso en casos en los que estas están separadas por punto ${ }^{24}$.

${ }_{24}$ Digo pues mi cuento (CORREAS 1627,191); asíque, como ya queda visto, no tuvo razon para ausentarse (REAL ACADEMIA 1771, 343); Salió, sin embargo, la sentencia a su favor (SALVÁ 1835, 703); «Si las pruebas son concluyentes, entonces viene bien el presentarlas separadamente, explanarlas, adornarlas, para que hieran más la imaginación y adquieran mayor fuerza 
4.- Finalmente, algunos - pocos- gramáticos han llegado a referirse explícitamente a clases de unidades de carácter textual o pragmático. Nos referimos a Gili Gaya y Alcina-Blecua en la tradición gramatical más reciente, pero también a Lenz y a Juan de Valdés, aunque este último desde una óptica distinta.

Los gramáticos hispánicos demuestran una visión de los hechos lingüísticos más amplia de lo que parece suponerse en este terreno. Desde luego que las observaciones reproducidas aquí constituyen una gota de agua dentro del enorme caudal que la tradición ha destilado a lo largo de los siglos; es cierto también que algunos de los comentarios aquí expuestos se prestan a la polémica. Pero lo importante es señalar que existe algo; aunque no se trate más que de observaciones lanzadas al paso de los problemas gramaticales que verdaderamente les interesaban, los mejores gramáticos de nuestro dominio lingüístico han demostrado, al ampliar sus observaciones a terrenos que estaban muy lejos de pisar, una amplitud de miras más grande, quizás, de la que demostramos hoy nosotros al negarnos a oír su voz.

\section{Bibliografía}

ACOSTA, L. (1984): «Las partículas modales del alemán y español». Studia Philologica Salmanticensia 7-8, : 7-41.

ALCINA FRANCH, J. y J.M. BLECUA (1975): Gramática española. Barcelona, Ariel.

ALONSO, A. y P.H. UREÑA (1938): Gramática castellana (2 vols): Buenos Aires, Losada.

BARRENECHEA, A.M. (1979): «Operadores pragmáticos de actitud oracional: los adverbios en -mente y otros signos». En AAVV (ed): Estudios lingüisticos y dialectológicos-temas hispánicos. Argentina, Hachette. 39-59.

BARTOL HERNÁNDEZ, J. Antonio (1988): Las oraciones causales en la Edad Media. Madrid, Paraninfo.

BAZZANELLA, C. (1990): «Phatic connectives as interactional cues in contemporary spoken Italian». Journal of Pragmatics 14, : 629-647.

BEINHAUER, W. (1929:1978 $\left.{ }^{3}\right)$ : El español coloquial. Madrid, Gredos.

BEINHAUER, W. (1965): «Dos tendencias analógicas en el lenguaje coloquial español (expresiones retardatarias, comodines, muletillas y expletivos». Español Actual VI, : 1-2.

todavía. Aunque esto debe tener su límite; porque si el orador se detiene demasiado en una prueba y apura cuanto se puede decir acerca de ella, llega a ser molesto, descubre el artificio, y hace que desconfíe el oyente o se distraiga» (BELLO 1847, 751); No tiene mucho, mucho que digamos: dos millones; yo tengo uno; CONQUE ya ves que para mí no es una ganga (REAL ACADEMIA 1917, 396), entre otros. 
BELLO, A. y R.J. CUERVO (1988: 1847): Gramática de la lengua castellana destinada al uso de los americanos. Madrid, Arco.

BERRENDONNER, A. (1983). «Connecteurs pragmatiques et anaphore». En (ed): Connecteurs pragmatiques et structure du discourse. Actes du $2 \grave{m}$ e Colloque de Pragmatique de Génève. Génève, Cahiers de linguistique française. 214-246.

BERRETTA, M. (1984). «Connettivi testuali in italiano e pianificazione del discorso». En (ed): Linguistica testuale (Atti del XV congresso della SLI. Roma, Bulzoni.

BRIZ GÓMEZ, A. (1993): «El papel argumentativo de los conectores pragmáticos en español coloquial». Contextos 11, 21-22.

BRIZ GÓMEZ, A. (1993): «Los conectores pragmáticos en español coloquial». Contextos 11, 21-22.

BRIZ GÓMEZ, A. (1994): «El papel metadiscursivo del conector pragmático en español». Actas del I Congreso de Lingüistica General. Valencia.

BUBLITZ, W. (1978): Ausdrucksweisen der Sprechereinstellung im Deutschen und Englischen. Tübingen, Max Niemeyer.

CALERO VAQUERA, M.L. (1986): Historia de la gramática española (18471920): Madrid, Gredos.

CORREAS, G. (1984:1627): Arte Kastellana. Santiago de Compostela, Universidad.

CORTÉS RODRÍGUEZ, L. (1991): Sobre conectores, expletivos y muletillas en el español hablado. Málaga, Ágora.

COVARRUBIAS OROZCO, S.d. (1611:1942): Tesoro de la lengua castellano española. Barcelona, Edición de Martín de Riquer.

CHAFE, W.L. (1982): «Integration y Involvement in Speaking, Writing and Oral Literature». En D. TANNEN (ed): Spoken y Written Language. Georgetown, Georgetown University Press. 35-53.

DIJK, Teun A. van (1980): Texto y contexto. Madrid, Cátedra.

FUENTES RODRÍGUEZ, C. (1987): Enlaces extraoracionales. Sevilla, Alfar. FUENTES RODRÍGUEZ, C. (1990): «Algunos operadores de función fática». En (ed): Sociolingüistica andaluza 5. Sevilla, Universidad. 137-170.

GILI GAYA, S. $\left(1983^{15}\right)$. Curso superior de sintaxis española. Barcelona, Vox. GIVON, Talmy (1979): «From discourse to syntax: grammar as a processing strategy». P. Cole (ed): Syntax and Semantics, 12. New York, Academic Press, 81-112. GÓMEZ ASENCIO, J.J. (1981): Gramática y categorías verbales en la tradición española 1771-1847. Salamanca, Universidad.

GÓMEZ ASENCIO, J.J. (1985): Subclases de palabras en la tradición española: 1771-1847. Salamanca, Universidad.

GUTIÉRREZ GALINDO, M.A. (1990): «Las definiciones de conjunción en los gramáticos latinos: un capítulo importante en la historia de la sintaxis». RSEL, XIX, 2: 389-419. 
HALLIDAY, M.A.K. y R. HASAN (1976): Cohesion in English. London, Longman.

HARTMANN, D. (1979): «Syntaktische Eigenschaften und syntaktische Funktionen der Partikeln eben, eigentlich, einfach, nämlich, ruhig, vielleicht und wohl». En H. WEYDT (ed): Die partikeln der deutschen Sprachen. Berlin, de Gruyter. 121-138.

HELBIG, G. (1977): «Partikeln als illokutiven Indikatoren im Dialog». Deutsch als Fremdsprache 14, 1: 30-43.

HOCKETT, C. (1958:1971). Curso de lingüística moderna. Buenos Aires, EUDEBA.

ISAZA CALDERÓN, B. (1967²). La doctrina gramatical de Bello. Madrid, Real Academia Española.

JIMÉNEZ PATÓN, B. (1614:1965): Epítome de la ortografía latina y castellana, Instituciones de la gramática española. Madrid, C.S.I.C.

KELLER, E. (1981). «Gambits: Conversational Strategy signals». En F. COULMAS (ed): Conversational routine: explorations in standardized communication situations and prepatterned speech. The Hague, Mouton. 93-113.

KRIVONOSOV, A. (1989): «Zur Problem der Klassifizierung der deutschen Partikeln». En H. WEYDT (ed): Sprechen mit Partikeln. Berlin, Gruyter. 30-38.

LAPESA, R. (1978). «Sobre dos tipos de subordinación causal». En (ed): Estudios ofrecidos a E. Alarcos Llorach. Oviedo, Universidad. 173-205.

LÁZARO CARRETER, Fernando (1949): Las ideas lingüísticas en España durante el siglo XVIII. Madrid.

LENZ, R. (1920): La oración y sus partes. Madrid, Revista de Filología Española.

LEWANDOWSKI, Th.(1982): Diccionario de Lingüistica. Madrid, Cátedra.

LOPE BLANCH, J.M. (1979): El concepto de oración en la lingüística española. México, U.N.A.M.

MADERO KONDRAT, Maribel (1983): «Los nexos en la Gramática de Andrés Bello». Homenaje a Andrés Bello. México, U.N.A.M.

MARTÍNEZ GARCÍA, H. (1991): «Del 'pues' temporal al 'causal' y 'continuativo'». En M. Á. Á. Martínez (ed) : Actas delXX Congreso de la SEL. Madrid, Gredos.

NARBONA JIMÉNEZ, A. (1986): «Problemas de sintaxis coloquial andaluza». RSEL 16, 2: 229-275.

NARBONA JIMÉNEZ, A. (1989): Sintaxis española: viejos y nuevos enfoques. Barcelona, Ariel.

NEBRIJA, A.d. (1980:1492). Gramática de la lengua castellana. Madrid, Editora nacional. 
PALACIOS DE SÁMANO, Margarita (1983): «Pronombres y adverbios relativos en la obra de Bello». Homenaje a Andrés Bello. México, U.N.A.M.

PONS BORDERÍA, Salvador (1994): « ¿Habla la tradición gramatical de los enlaces extraoracionales?» Actas del I Congreso de Lingüística General. Valencia.

PONS BORDERÍA, Salvador (1995a): «La presencia de los enlaces extraoracionales en la tradición gramatical española: La clasificación de las conjunciones». Anuario de Lingüistica Hispánica.

PONS BORDERÍA, Salvador (1995b): «La presencia de los enlaces extraoracionales en la tradición gramatical española: La figura de Andrés Bello». Moenia, I.

QUASTHOFF, U. (1979). «Verzögerungsphänomene, Verknüpfungs- und Gliederungssignale in Alltagsargumentationen und Alltagserzählungen». En H. WEYDT (ed): Die partikeln der deutschen Sprachen. Berlin, de Gruyter. 39-57.

RAMAJO CAÑO, A. (1987): Las gramáticas de la lengua castellana de Nebrija a Correas. Salamanca, Universidad.

REAL ACADEMIA, E. (1771): Gramática de la Lengua Castellana. Madrid, Imprenta de Joaquín de Ibarra.

REAL ACADEMIA, E. (1796): Gramática de la Lengua Castellana. Madrid, Imprenta de la viuda de D. Joaquín de Ibarra.

REAL ACADEMIA, E. (1854): Gramática de la Lengua Castellana. Madrid, Imprenta nacional.

REAL ACADEMIA, E. (1917): Gramática de la Lengua Castellana. Madrid, Perlado Páez y compañía.

REAL ACADEMIA, E. (1931): Gramática de la Lengua Española. Madrid, Espasa-Calpe.

REAL ACADEMIA, E. (1973): Esbozo de una nueva gramática de la lengua española. Madrid, Espasa-Calpe.

ROJO, G. (1978). Cláusulas y oraciones. Santiago de Compostela, Verba (anejo).

SALVA, V. (1988: 1835): Gramática de la lengua castellana. Madrid, Arco (ed. de margarita Lliteras):

SANCHEZ DE LAS BROZAS, F. (1976: 1664): Minerva sive de Causis Latinae Linguae Commentarius. Madrid, Cátedra.

SCHEGLOFF, E. y H. SACKS (1973): «Opening up closings». Semiotica 7, : 289-327.

SCHIFFRIN, D. (1987). Discourse markers. Cambridge, Cambridge University Press.

SECO, R. (1963 $\left.{ }^{10}\right)$ : Manual de gramática española. Madrid, Aguilar.

SORNICOLA, R. (1981): Sul parlato. Bologna, Il Mulino.

VALDÉS, J.d. (1535:1983): Diálogo de la lengua. Barcelona, Orbis. 
VILLALÓN, L. (1558:1971): Gramática castellana. Madrid, C.S.I.C.

WEYDT, H. (1969): Abtönungspartikeln. Berlin, Bad Homburg.

YNDURÁIN, F. (1965): «Más sobre lenguaje coloquial». EA VI, 3-4.

ZIERER, E. (1982): «Las partículas ilocutivas eben, halt y ja del alemán y sus equivalentes en español». Lenguaje y Ciencias 22, 3: 59-70. 